\title{
Evaluating the Digital Storage Requirements for a Partial Picture Archive and Communication System
}

\author{
G. Battaglia, R. Maroldi, and A. Chiesa
}

\begin{abstract}
The study evaluates the volume of digital images produced in a department of diagnostic imaging, with the primary goal of identifying the requirements of digital storage for a partial picture archive and communication system (PACS). The daily activity of digital units lone computed tomography unit, one magnetic resonance imaging, two ultrasonography. and one digital subtraction angiographyl, which perform 25\% of total examinations in the department, was analyzed to determine the number of images produced by digital techniques. They account for $65 \%$ to $70 \%$ of the total images. The storage capacity necessary to contain all digital data produced in a 800-bed hospital reaches nearly 100 Gbyte/yr without compression. The study emphasizes that a partial PACS can be economically justified through reduced film-archiving costs. This goal could be achieved through a selection of significant images and examinations, considerably reducing the cost of film reproduction and allowing the amortization of a partial PACS in about 5 or 6 years.

(C) 1990 by W.B. Saunders Company.
\end{abstract}

KEY WORDS: PACS, digital images, data storage.

$\mathbf{T}$ he increasing application of digital techniques in diagnostic imaging, and the present trends of information science, make the introduction of computerized systems for the management of radiological images feasible and cost effective in technologically advanced clinical sites. These systems are called PACS (picture archive and communication system) ${ }^{1,2}$ While conventional (analog) radiology encounters stable or reduced examination workloads, digital radiology shows a definite increase. ${ }^{3,4}$ This trend relates to the increasing number of digital examinations, images per examination, and volume of data per image. This evolution makes foreseeable in the next years a totally digitized department of diagnostic imaging based on PACS technology. ${ }^{5,6}$

When planning a PACS, it is strategically important to plan a modular phasing-in period,

From the Department of Diagnostic Imaging, University of Brescia, Spedali Civili, Brescia, Italy.

Address reprint requests to Giuseppe Battaglia, $M D$, Department of Diagnostic Imaging, University of Brescia, Spedali Civili, 25125 Brescia, Italy.

(c) 1990 by W.B. Saunders Company.

0897-1889/90/0301-0012\$03.00/0 permitting a gradual implementation. In fact, staggering the installation of components over time reduces costs and possible mistakes. The most important prerequisites are the identification of all features that should characterize the system's components and the definition of all phases that would implement a PACS. ${ }^{7,8}$ Therefore, a preliminary analysis of the characteristics of the following systems is required:

1. acquisition of digital images (direct acquisition or conversion from analogic images $)^{1,9}$;

2. storage of digital data (storage capacity, access-time to stored data, storing devices, compression ratio, safety) ${ }^{10,11,12,13}$;

3. transmission of digital data (speed and relationship with costs, users $)^{14}$; and

4. visualization of images (solution for different displays). ${ }^{1}$

The analysis should include problems related also to the software updating and to the hardcopy production. ${ }^{15}$ A careful planning of this phase permits a correct preliminary evaluation of funds needed for the project and allows some cost savings on instruments that are helpful during the project but unnecessary in the PACS final version. $^{7}$

At the Department of Diagnostic Imaging of the University of Brescia, a project for a PACS application is being considered; it tries to manage the images produced by computed tomography (CT), magnetic resonance imaging (MRI), ultrasonography (US), and digital subtraction angiography (DSA), ultimately integrating them into a system that digitizes analog images.

At present the most important question concerning implementation of a PACS does not pertain to either technology or planning, but to the cost-benefit ratio. Therefore, it appears extremely important to notice that the high cost of a PACS seems to be partially justified by a remarkable reduction in film costs.

The project refers to a "partial PACS", because of the high number of analog images still produced; it has to be modular to allow for future modifications to be introduced into the department (which serves an 800-bed teaching hospital). 
Table 1. Digital Imaging Modalities (Department of Diagnostic Imaging, University of Brescia)

\begin{tabular}{llll}
\hline $\begin{array}{c}\text { Digital Imaging } \\
\text { Modality }\end{array}$ & \multicolumn{1}{c}{ Equipment } & $\begin{array}{c}\text { Resolution } \\
\text { (Pixels and Bits/Pixel) }\end{array}$ & Hard-copy Modalities \\
\hline CT & Siemens Somatom DR2 & $256 \times 256 \times 16$ & Laser printer \\
MR & Siemens Magnetom 1,5T & $256 \times 256 \times 16$ & Laser printer \\
US & Toshiba SA 100 & $512 \times 512 \times 16$ & Polaroid \\
& Ansaldo AU920 & $512 \times 512 \times 6$ & \\
DSA & Siemens Angiotron CMP & $512 \times 512 \times 12$ & Laser printer \\
\hline
\end{tabular}

This study refers to the planning phase of the PACS. Its main goal is the evaluation of the daily volume of digitally acquired images, as this volume plays an important role in determining the storage capacity that the partial PACS requires.

At the same time, the study analyzes the number of digital images needing reproduction on film as hard copies. ${ }^{1,16,17}$

\section{MATERIAL AND METHODS}

The investigation was performed during a 2-week period in the first half of 1989 , evaluating the total activity of all digital equipment (CT, MRI, US, and DSA).

Table 1 lists the different digital devices, the resolution of all digital images, and the hard-copy modality. The data collected deal with the daily number of examinations; the number of images per examination, and per day; the number of films used for hard copies (including extra copies for outpatients); and the percentage of these extra copies.

It is important to notice that a remarkable percentage of examinations (15\%) requires a second copy on film for different reasons (outpatients, departmental archives, surgical emergencies, etc).

Finally, data recording digital examinations are compared with data regarding analog techniques, in order to evaluate the effectiveness of a PACS. ${ }^{4.9}$

\section{RESULTS}

\section{Computed Tomography}

The activity on the CT unit is shared between "brain" and "body" examinations, the central nervous system examinations definitely prevailing (77\%) (Table 2). Neurological CT has a daily workload of 25 to 30 examinations. The number of images per examination ranges from 10 to 45 or 50 , with an average of 17 images per examination. The average values are 16 images per examination for brain CT without contrast media, 18.5 images per examination for brain CT with contrast media, and 20 images per examination for spine CT. Images acquired are about 400 to 500 per day. Hard copies from neuro-CT examinations are made by a laser printer, formatting the images on different sizes $(1,4,6,12)$; the 12-image format is the most common presentation $(91 \%)$.

In 1 day, 64 films (extra copies included) are processed; the average production is 2 to 3 films for each brain CT examination and 3 to 4 films for each spine $\mathrm{CT}$ examination.

One or more extra copies are made in $32 \%$ of all neurological CT examinations.

On each day, 6 to 8 body CT examinations are performed. The number of images per examination varies from 20 to 70 , with an average of 42 . The daily production of images is between 290 and 300 .

Some CT examinations require a greater number of images because of the use of different "windows."

The daily production of body CT hard copies requires about 50 films (extra copies included). Extra copies are always made for outpatients, and some wards demand extra copies. This means that $57 \%$ of body CT examinations are reproduced twice on films.

Table 2. Computed Tomography

\begin{tabular}{lccccc}
\hline \multicolumn{1}{c}{ CT Procedure } & $\begin{array}{c}\text { Exams } \\
\text { Per Day } \\
\text { (Average) }\end{array}$ & $\begin{array}{c}\text { Images } \\
\text { Per Exam } \\
\text { (Average) }\end{array}$ & $\begin{array}{c}\text { Images } \\
\text { Per Day } \\
\text { (Average) }\end{array}$ & $\begin{array}{c}\text { Films for } \\
\text { Hard-copy } \\
\text { (Average) }\end{array}$ & $\begin{array}{c}\text { Films for } \\
\text { Extra-copy } \\
\text { (Average) }\end{array}$ \\
\hline Brain & 22.0 & 16.6 & 365.2 & 53.1 & $25.2 \%$ \\
Spine & 3.3 & 20.0 & 66.0 & 10.3 & $23.2 \%$ \\
Tumor Staging & 1.3 & 58.0 & 75.4 & 18.6 & $50.0 \%$ \\
Abdomen and Pelvis & 2.4 & 43.1 & 103.4 & 11.2 & $17.0 \%$ \\
Head and Neck & 1.0 & 30.1 & 30.1 & 5.4 & $43.4 \%$ \\
Other & 2.5 & 37.8 & 94.4 & 16.1 & $34.3 \%$ \\
Total & 32.5 & 22.6 & 734.5 & 114.7 & $30.0 \%$ \\
\hline
\end{tabular}


Table 3. Magnetic Resonance

\begin{tabular}{|c|c|c|c|c|c|}
\hline MR Procedure & $\begin{array}{c}\text { Exams } \\
\text { Per } \\
\text { Day } \\
\text { (Average) }\end{array}$ & $\begin{array}{l}\text { Images } \\
\text { Per } \\
\text { Exam } \\
\text { (Average) }\end{array}$ & $\begin{array}{c}\text { Images } \\
\text { Per } \\
\text { Day } \\
\text { (Average) }\end{array}$ & $\begin{array}{l}\text { Films } \\
\text { for } \\
\text { Hard-copy } \\
\text { (Average) }\end{array}$ & $\begin{array}{l}\text { Films for } \\
\text { Extra- } \\
\text { copy } \\
\text { (Average) }\end{array}$ \\
\hline Brain & 3.2 & 34.0 & 108.8 & 10.2 & - \\
\hline Spine & 1.8 & 25.9 & 46.6 & 4.5 & 一 \\
\hline Head and Neck & 0.6 & 26.5 & 15.9 & 1.6 & 一 \\
\hline Abdomen & 0.9 & 37.2 & 33.5 & 3.0 & 一 \\
\hline Pelvis & 0.5 & 45.3 & 22.7 & 2.2 & - \\
\hline Other & 1.5 & 30.4 & 45.6 & 4.8 & - \\
\hline Total & 8.5 & 32.1 & 273.1 & 26.8 & - \\
\hline
\end{tabular}

\section{Magnetic Resonance Imaging}

The activity of the unit is split between brain and body examinations (Table 3 ). About five MR neurological examinations are performed each day ( $64 \%$ brain and $36 \%$ spine). Brain examinations require about 34 images per examination, and spine examinations about 26. Daily images number about 160 . Approximately 35 films are printed each day, more than $65 \%$ for brain MR. Body MR examinations number about 7 to 8 per day. A body MR examination requires 30 to 35 images, depending on the anatomical region, the type of lesion, and the sequences used. Images taken are about 125 per day. The average number of films used for body MR examinations is 12 per day.

No extra copies are made for neuro-MR and body MR examinations.

\section{Ultrasonography}

About 24 ultrasound examinations are performed on each working day (Table 4). Most of the studies concern the liver $(46 \%)$ and the kidney (21\%). The images are reproduced on Polaroid films (Polaroid Corp, Cambridge, MA) and are stored manually in the archive of the department.

The number of images taken is highly dependent on the radiologist who decides which image should be printed because of its diagnostic significance. About 170 images per day are made, most of them being two images on the same Polaroid hard copy.

\section{Digital Subtraction Angiography}

Angiographic examinations using a digital technique are almost exclusively performed through arterial selective injection (Table 5).

The angiographic unit also allows image acquisition on radiographic film. This modality is seldom used for those examinations which require high spatial resolution. Two to four examinations are performed each day. The number of digital images can vary significantly, from a minimum of 3 to a maximum of 17 (with an average of 6.5 images per examination). The images acquired are about 20 per day, and 8 to 9 films are processed each day.

Copies are required on about $22 \%$ of examinations (films for extra copies total 28\%). Images are printed by a laser printer, four images per film.

\section{Estimate of the Storage Capacity for a Future PACS}

The estimated volume of the PACS file needed to manage the data produced by the different imaging modalities can be calculated from the evaluation of each individual digital acquisition unit (Table 6). The total number of bytes produced daily by a digital imaging technique is given by the following formula ${ }^{4}$ :

$$
\begin{aligned}
\text { no. bytes } & =\frac{\text { matrix } \times \text { bits } / \text { pixel }}{8} \\
& \times \text { no. exams } / \text { day } \times \text { no. images } / \text { exam. }
\end{aligned}
$$

To manage all the data produced yearly by the

\begin{tabular}{|c|c|c|c|c|c|}
\hline US Procedure & $\begin{array}{c}\text { Examinations } \\
\text { Per } \\
\text { Day } \\
\text { (average) }\end{array}$ & $\begin{array}{c}\text { Images } \\
\text { Per } \\
\text { Examination } \\
\text { (average) }\end{array}$ & $\begin{array}{c}\text { Images } \\
\text { Per } \\
\text { Day } \\
\text { (average) }\end{array}$ & $\begin{array}{l}\text { Films } \\
\text { for } \\
\text { Hard Copy } \\
\text { (average) }\end{array}$ & $\begin{array}{l}\text { Films for } \\
\text { Extra } \\
\text { Copy } \\
\text { (average) }\end{array}$ \\
\hline Liver & 11.1 & 6.5 & 72.2 & 36.0 & - \\
\hline Kidney & 4.9 & 7.8 & 38.2 & 19.0 & - \\
\hline Upper Abdomen & 4.2 & 8.6 & 36.1 & 19.0 & - \\
\hline Neck & 1.6 & 6.6 & 10.6 & 5.2 & - \\
\hline Other & 1.9 & 7.5 & 14.3 & 6.5 & - \\
\hline Total & 23.7 & 7.2 & 171.4 & 85.7 & - \\
\hline
\end{tabular}

Table 4. Ultrasound 
Table 5. Digital Subtraction Angiography

\begin{tabular}{|c|c|c|c|c|c|}
\hline DSA Procedure & $\begin{array}{c}\text { Examinations } \\
\text { Per } \\
\text { Day } \\
\text { (average) }\end{array}$ & $\begin{array}{c}\text { Images } \\
\text { Per } \\
\text { Examination } \\
\text { (average) }\end{array}$ & $\begin{array}{l}\text { Images } \\
\text { Per } \\
\text { Day } \\
\text { (average) }\end{array}$ & $\begin{array}{c}\text { Films } \\
\text { per } \\
\text { Hard Copy } \\
\text { (average) }\end{array}$ & $\begin{array}{l}\text { Films for } \\
\text { Extra } \\
\text { Copy } \\
\text { (average) }\end{array}$ \\
\hline Inferior Limbs & 1.2 & 5.7 & 6.8 & 2.4 & - \\
\hline Brachiocephalic V. & 1.4 & 7.2 & 10.1 & 4.2 & $33.3 \%$ \\
\hline Abdominal Vessels & 0.5 & 6.8 & 3.4 & 2.0 & $50.0 \%$ \\
\hline Total & 3.1 & 6.5 & 20.3 & 8.6 & $28.0 \%$ \\
\hline
\end{tabular}

digital modalities presently operating at the Department of Diagnostic Imaging of the University of Brescia (Table 7), a storage capacity of about 50 Gbyte (1 GByte $=1,000$ Mbyte) per year will be necessary. The volume of data concerning information on patients (identification and personal data, clinical data) is not very relevant, because it represents only about a thousandth of the volume required by the image data. ${ }^{18}$

Therefore, the project for a partial PACS at the University of Brescia has to include a file with a storage capacity of about $100 \mathrm{Gbyte} / \mathrm{yr}$; this capacity is able to manage not only the present digital production but also the production of the near future. These figures can be partially reduced by means of a suitable nondestructive compression. It must be stressed that a storing policy which intends to store with the original resolution only the significant images and with a reduced resolution those images which are not relevant for the diagnosis, would allow a marked reduction of the storage capacity required. ${ }^{19}$ A PACS file should have a storage capacity large enough to contain all digital data that will be produced in 1 year.

\section{Digital and Analog Comparison}

When considering the usefulness of a partial PACS, the evaluation of the proportion of digital versus analog examinations appears extremely important, since this evaluation can justify an investment that is highly relevant from an eco-

\begin{tabular}{ccc}
$\begin{array}{c}\text { Table 6. Relationship Between Digital Procedures and } \\
\text { Images Produced. Distribution of Digital Imaging Modalities }\end{array}$ \\
\hline Imaging & $\begin{array}{c}\text { Overall } \\
\text { Procedures }\end{array}$ & $\begin{array}{c}\text { Images } \\
\text { Produced }\end{array}$ \\
\hline Modality & $48 \%$ & $61 \%$ \\
CT & $35 \%$ & $14 \%$ \\
US & $5 \%$ & $2 \%$ \\
DSA & $12 \%$ & $23 \%$ \\
MR & $100 \%$ & $100 \%$ \\
Total & &
\end{tabular}

nomic point of view. ${ }^{4}$ At present, PACS always coexists with a significant production of radiographic films ${ }^{20}$ (Table 8).

Digital examinations represent more than $25 \%$ of all investigations performed at the department. This percentage reaches the upper limits of the data mentioned in the previous surveys. ${ }^{1,4,9,21}$

Moreover, if the comparison is made between the number of images produced by the analog technique and those produced by digital modalities, it appears that digital images account for more than $25 \%$; actually, they make up $65 \%$ to $70 \%$ of all produced images.

\section{DISCUSSION}

During the investigation period, a daily average of 68 digital examinations was observed, with an output of about 1,200 images per day.

Each day, 150 to 160 films are printed by the two laser printers; $75 \%$ of them are for CT examinations, $20 \%$ for MR examinations, and $5 \%$ for DSA examinations. These figures include reconstructed images and specific postprocessing images made for diagnostic goals.

Hard copies that are not printed by the laser printers (Polaroid hard copies [for US] make up $35 \%$ of the total. Extra copies are required in $14 \%$ of the total digital examinations. They are produced in more than $25 \%$ of $\mathrm{CT}$ examinations and in $38.7 \%$ of DSA examinations.

Table 7. Digital Data Volumes Per Year

\begin{tabular}{lccccr}
\hline $\begin{array}{c}\text { Imaging } \\
\text { Modality }\end{array}$ & $\begin{array}{c}\text { Spatial } \\
\text { Resolution } \\
\text { (pixels) }\end{array}$ & $\begin{array}{c}\text { Contrast } \\
\text { Resolution } \\
\text { (bits/pixel) }\end{array}$ & $\begin{array}{c}\text { Mbyte/ } \\
\text { Image }\end{array}$ & $\begin{array}{c}\text { Mbyte/ } \\
\text { day }\end{array}$ & Mbyte/yr * \\
\hline CT & $256 \times 256$ & 12 & 0.10 & 73.5 & 18,375 \\
MR & $256 \times 256$ & 16 & 0.13 & 36.3 & 9,075 \\
US & $512 \times 512$ & $12 \dagger$ & 0.39 & 66.8 & 16,700 \\
DSA & $512 \times 512$ & 12 & 0.39 & 7.9 & 1,975 \\
Total & & & & & 46,125 \\
\hline *250 days/yr. & & & & & \\
TAverage.
\end{tabular}


Table 8. Analog Versus Digital Procedures

\begin{tabular}{|c|c|c|c|c|c|}
\hline $\begin{array}{c}\text { Analog } \\
\text { Procedures }\end{array}$ & Examinations/yr & Images/yr * & $\begin{array}{c}\text { Digital } \\
\text { Procedures }\end{array}$ & Examinations/yr & Images/yr \\
\hline Respiratory & 24,000 & 72,000 & $\mathrm{CT}$ & 8,125 & 183.600 \\
\hline Skeletal & 11,400 & 34,200 & MR & 2,125 & 68,200 \\
\hline Cranial & 7,200 & 21,100 & US & 5,925 & 42,700 \\
\hline Gastrointestinal & 3,600 & 10,800 & DSA & 775 & 5,000 \\
\hline Genitourinary & 600 & 1,800 & & & \\
\hline \multirow[t]{2}{*}{ Total } & 46,800 & 139,900 & & 16,950 & 299,500 \\
\hline & $(73.4 \%)$ & $(31.8 \%)$ & & $(26.6 \%)$ & $(68.2 \%)$ \\
\hline
\end{tabular}

*Three images per examination.

\section{Economic Evaluation}

The economic justification of a partial PACS can result from the reduction in film-archiving costs as the use of electronic means permits.

To estimate the possible cost savings, a comparison was made between the cost of digital images reproduction on films and the cost of a partial PACS.

The present cost of the digital images' hard copies is $\$ 1.1$ million on a 5 -year basis; the price of a $14 \times 17$-in laser film is $\$ 6.00$; the price of Polaroid film is $\$ 1.00$.

Using a partial PACS, two different possibilities of image reproduction are possible:

1. Reproduction of some significant images of each examination, selected by the radiologist. Hard copies of the full set of images are not produced. In this case the cost of film could be considerably reduced ( $\$ 360,000$ in 5 years).

2. Reproduction on films of a part of examinations (those for which a second copy is presently produced: about $15 \%$ of all digital examinations). Only selected images are reproduced also in this case. The film cost is considerably reduced ( $\$ 135,000$ in 5 years).

The cost of a partial PACS (including two workstations for the Department of Radiology, four display units for the surgical and neurological departments, a local network and file server, and two jukeboxes with 50 optical disks, 3.7
Gbyte each) is estimated at $\$ 950,000$. These two solutions allow a savings on digital-image reproduction of $\$ 740,000$ or $\$ 965,000$ in 5 years.

The cost can be recovered in about 6 years if the reproduction of significant images of all the examinations is chosen; the cost can be recovered in about 5 years if the reproduction is limited to the significant images of only those examinations that are required by the $\mathrm{x}$-ray department or by the patient.

The cost can be further reduced if the images are reproduced in a different way (paper hard copy).

\section{CONCLUSIONS}

The department in which the survey was performed is mainly oriented to surgical diseases. This is one of the reasons that digital investigations are particularly frequent $(25 \%)$ and that the percentage of digital images obtained $(65 \%$ to $70 \%$ ) is higher than that of conventional analog images.

It should also be considered that the future of digital radiography will certainly lead to a further increase of digital examinations and images. ${ }^{22}$

The realization of a completely digital Department of Diagnostic Imaging appears still remote. ${ }^{4}$ In the future, however, the percentage of digital examinations is likely to increase to such an extent that the break-even point will be reached, thus economically justifying the realization of partial PACS. ${ }^{4}$

\section{REFERENCES}

1. Greinacher CFC: System architecture and functionality of the structured Siemens PACS, in Chiesa A, Gasparotti $\mathbf{R}$, Maroldi R (eds): Planning Considerations in Diagnostic Imaging and Radiation Therapy. Proceedings of the Fifth International Symposium on the Planning of Radiological Departments. Florence, Italy, Class Publ, 1988, pp 212-224

2. Mun SK, Benson H: Fast-paced progress in computers ensures feasibility of PACS. Diagnostic Imaging 4:106-116, 1987

3. De Valk JPJ, Bakker AR, Bijl K, et al: PACS reviewed: possible and coming soon? Journal of Medical Imaging 1:77-84, 1987

4. Lemke HU: Picture Archiving and Communication Systems, in Chiesa A, Gasparotti R, Maroldi R (eds): 
Planning Considerations in Diagnostic Imaging and Radiation Therapy. Proceedings of the Fifth International Symposium on the Planning of Radiological Departments. Florence, Italy, Class Publ, 1988, pp 198-208

5. Gitlin JN, Arenson RL, Curtis JW, et al: Satellite trasmission of radiographic images, in Chiesa A, Gasparotti R, Maroldi R (eds): Planning Considerations in Diagnostic Imaging and Radiation Therapy. Proceedings of the Fifth International Symposium on the Planning of Radiological Departments. Florence, Italy, Class Publ, 1988, pp 250-254

6. De Simone D, Kundel HL, Arenson RL et al: The effect of a digital imaging network on physician consultation, in Chiesa A, Gasparotti R, Maroldi R (eds): Planning Considerations in Diagnostic Imaging and Radiation Therapy. Proceedings of the Fifth International Symposium on the Planning of Radiological Departments. Florence, Italy, Class Publ, 1988, pp 231-234

7. Cannavo MJ: Low-risk strategy for PACS calls for modular phase-in, Diagnostic Imaging 7:135-145, 1988

8. Sternick ES, Zamenhof RG, Curran BH, et al: Planning the filmless radiology department: a systems approach. Fourth International Symposium on the Planning of Radiological Departments, Book of Papers, Puerto Rico, 1984, pp 246-248

9. Abernathy DL: PACS may be technically feasible but are they cost-effective? Diagnostic Imaging 12:27-30, 1983

10. Schwenker RP: Digital image management, in Chiesa A, Gasparotti R, Maroldi R (eds): Planning Considerations in Diagnostic Imaging and Radiation Therapy. Proceedings of the Fifth International Symposium on the Planning of Radiological Departments. Florence, Italy, Class publ, 1988, pp 231-234

11. Hindel R, Blume H, Balter S: Communication patterns in a digital department. Fourth International Symposium on the Planning of Radiological Departments, Book of Papers, Puerto Rico, 1984, pp 269-272

12. Mankovich NJ, Taira RK, Cho PS, et al: Operational radiologic image archive on digital optical disks. Radiology $167: 139-142,1988$

13. Huang HK, Mankovich NJ, Cho PS, et al: Picture Archiving and Communication Systems in Japan. AJR 148:427-429, 1987
14. Spackman TJ, Bensman KW: Development of a useful Picture Archiving and Communications System. AJR 148: 1025-1026, 1987

15. Cory DA, Cohen MD: Site planning considerations for a laser imager, in Chiesa A, Gasparotti R, Maroldi R (eds): Planning Considerations in Diagnostic Imaging and Radiation Therapy. Proceedings of the Fifth International Symposium on the Planning of Radiological Departments, Florence, Italy, Class Publ, 1988, pp 123-125

16. Drew PG: Cost effectiveness analysis for PACS. Fourth International Symposium on the Planning of Radiological Departments, Book of Papers, Puerto Rico, 1984, pp 259-265

17. Dwyer SJ, et al: The cost of managing digital diagnostic images. Radiology 143:313-318, 1982

18. Barneveld Binkhuysen FH, ter Haar Romeny BM, Andriessen $\mathrm{JH}$, et al: The setup of a clinical evaluation of the Dutch PAC System, in Chiesa A, Gasparotti R, Maroldi R (eds): Planning Considerations in Diagnostic Imaging and Radiation Therapy. Proceedings of the Fifth International Symposium on the Planning of Radiological Departments, Florence, Italy, Class Publ, 1988, pp 239-241

19. Schneider GH, Gell G, Becker M, et al: Practical experiences with a PACS in a CT station, in Chiesa A, Gasparotti R, Maroldi R (eds): Planning Considerations in Diagnostic Imaging and Radiation Therapy. Proceedings of the Fifth International Symposium on the Planning of Radiological Departments, Florence, Italy, Class publ, 1988, pp 242-246

20. Lambrecht LG, Marion JL: Assessment of economic and other criteria for the justification of PACS, in Chiesa A, Gasparotti R, Maroldi R (eds): Planning Considerations in Diagnostic Imaging and Radiation Therapy. Proceedings of the Fifth International Symposium on the Planning of Radiological Departments, Florence, Italy, Class Publ, 1988, pp 235-238

21. Ramsby GR: PAC system reliably handles all-digital department. Diagnostic Imaging 7:148-152, 1987

22. Arenson RL, Seshadri SB, Kundel HL, et al: Clinical evaluation of a medical image management system for chest images. AJR 150:55-59, 1988 